International Journal of Dentistry and Oral Science (IJDOS)

ISSN: 2377-8075

\title{
Metabolism Of L929 Cells After Contact With Acrylic Resins. Part 1: Acrylic Denture Base Resins
}

Silva CRC, Pellissari CV, Sanitá PV, Amaya MI, Masetti P, Jorge JH*

Department of Dental Materials and Prosthodontics, Araraquara Dental School, Univ. Estadual Paulista, UNESP, São Paulo, Brazil.

\section{Abstract}

Objective: The purpose of this study was to evaluate the effectiveness of complementary heat treatment and water storage in reducing cytotoxicity of acrylic resins denture bases used in Brazil by the MTT assay.

\begin{abstract}
Material and Methods: First, nine specimens were fabricated from metal matrix in the form of discs with $14 \mathrm{~mm}$ in diameter and $1.2 \mathrm{~mm}$ of thick. Immediately after making, 24 or 48 hours after storage in distilled water, the samples of heat-polymerized resins were divided into 3 groups $(n=3)$ according to the type of thermal treatment: Group 1: samples were individually exposed to microwave energy ( $500 \mathrm{~W}$ for 3 minutes); Group 2: samples were immersed in water at $55^{\circ} \mathrm{C}$ for 60 minutes; Group 3: samples did not receive heat treatment. To prepare the extracts, 3 samples of each group were placed into vials containing $3 \mathrm{~mL}$ of culture medium and stored at $37^{\circ} \mathrm{C}$ for 24 hours. L929 cells were used and the MTT assay was performed to analyze the cellular metabolism. Two-factor analysis of variance was used to detect significant among groups at $5 \%$ significance.
\end{abstract}

Results: After statistical analysis, the materials were classified according to the cytotoxic effect: non-cytotoxic, slightly cytotoxic; moderately cytotoxic; and strongly cytotoxic. The results showed that the resins ranged from moderately cytotoxic to non-cytotoxic, but no statistically significant difference among experimental groups. Furthermore, the water storage and thermal treatments reduced the cytotoxicity of the resins.

Conclusions: It was concluded that the resins studied are potentially toxic and that treatments can decrease their cytotoxicity.

Keywords: Acrylic resin; Heat treatment; Cytotoxicity.

\section{*Corresponding Author:}

Janaina Habib Jorge,

Department of Dental Materials and Prosthodontics, Araraquara Dental School, Univ. Estadual Paulista, UNESP, Postal address: Rua Humaitá, 1680, Centro; Araraquara, SP, Brazil.

Tel: 55 (16) 3301-6550

E-mail: janainahj@foar.unesp.br

Received: March 24, 2015

Accepted: April 22, 2015

Published: April 24, 2015

Citation: Jorge JH, et al., (2015) Metabolism Of L929 Cells After Contact With Acrylic Resins. Part 1: Acrylic Denture Base Resins. Int J Dentistry Oral Sci. S1:001, 1-5. doi: http://dx.doi.org/10.19070/2377-8075SI01001

Copyright: Jorge $\mathbf{J H}^{\odot}$ 2015. This is an open-access article distributed under the terms of the Creative Commons Attribution License, which permits unrestricted use, distribution and reproduction in any medium, provided the original author and source are credited.

\section{Introduction}

The material of choice for making bases of partial or full denture have been acrylic resins due to some advantages, such as satisfactory dimensional stability and fracture resistance, easy handling and repair, better thermal conductivity and considerable color stability, which allow imitating natural gum [1]. The most of these materials is composed of the polymer mixture containing benzoyl peroxide and a monomer, typically methyl methacrylate. The polymerization reaction of the material occurs by rapid decomposition of the peroxide after having been activated; it releases a significant amount of free radicals, and polymerizing the monomer throughout the polymer blend [2]. Benzoyl peroxide can be activated by chemicals generally incorporated into the monomer by light or heat by means of microwaves, a hot water bath or dry heat in an oven. However, the conversion of monomer to polymer is not complete and the unreacted monomer that is called residual monomer [3, 4]. This monomer in contact with the mucosa, may act as an irritant or cause allergic reactions. The most common clinical signs and symptoms are redness, erosion in the oral mucosa, burning in the mucosa and tongue [5]. Histologically, it can be observed inflammatory infiltrate and increased keratin layer in the areas of mucosa in contact with the prosthesis.

In the case of heat-polymerized resins, the level of residual monomer decreases with the increasing curing time and increases with decreasing temperature $[3,6]$. With respect to the curing cycles, it has been found that resins with rapid cycle releases higher levels of residual monomer [6]. Moreover, Jorge et al. [7] reported that long cycle acrylic resin Lucitone 550 reduced the number of vi- 
able cells compared to the short cycle, probably because it do not reach the glass transition temperature of the resin. In addition, when it is used this cycle in resins which do not have indication, the monomer levels can increase up to seven times when compared to a resin polymerized using long cycle (greater than 6 hours) [8].

To avoid adverse reactions, as well as to decrease the amount of residual monomer, several authors have suggested soaking dentures in water before placing on the patient [9-11]. The use of microwave energy can be considered another type of treatment that could trigger further polymerization reaction $[9,12,7,10]$. Thus, irradiation of microwaves and storage of dentures in water could be considered alternative methods for reducing the cytotoxicity of acrylic resins $[9,10]$.

The resins for making foundations have shown varying degrees of cytotoxicity in vitro and allergic responses in vivo, probably due to unreacted components during the polymerization process or reaction of the byproducts. Studies have shown that potentially toxic substances originated from base resins include methyl methacrylate, formaldehyde, methacrylic acid, and benzoic acid [13]. These toxic components, widespread in aqueous media, may be able to act even in distant locations of the resin contact area [14]. Thus, large areas of mucosa can be exposed to toxic components over a long period of time [13]. The current acrylic resins also contain additives that have not been widely studied, so are likely responsible for hypersensitivity reactions [9-11].

Some tests have been used to determine the cytotoxicity of materials such as MTT (methyl tetrazolium salt) test, which reflects the cellular metabolism through mitochondrial activity. With them it can be observed, through the cell culture method, proliferation or cell growth inhibition resulting from contact with cytotoxic substances.

Many studies have been conducted to test the cytotoxicity of acrylic resins for base and reline dentures [9-11]. However, such studies are based on imported resins rarely used in different laboratories prosthesis in Brazil. Based on this information, it was found advisable to evaluate the effectiveness of complementary heat treatments and storage in water on the cytotoxicity of denture acrylic base resins used in Brazil through the test that assesses mitochondrial activity of viable cells.

\section{Material and Methods}

Samples of each resin were fabricated under aseptic conditions from the metal matrix in the form of discs with $14 \mathrm{~mm}$ in diameter and $1.2 \mathrm{~mm}$ thick. Samples were produced according to the manufacturer's protocol. Lucitone 550 was processed for $90 \mathrm{~min}$ at $73^{\circ} \mathrm{C}$ and then in $100^{\circ} \mathrm{C}$ boiling water for $30 \mathrm{~min}$ (short cycle). Acrylic resin Wave Vipi was polymerized by microwave for 20 minutes at $20 \%$ potency, followed by 5 minutes at $60 \%$ potency in a domestic microwave maximum potency of $800 \mathrm{~W}$. The Onda Cryl resin was polymerized in 3 steps: 3 minutes at $40 \%$ potency, followed by 4 minutes of rest and 3 minutes at $90 \%$ potency, also in domestic microwave maximum output of $800 \mathrm{~W}$. The resin Clássico was polymerized for 9 hours at $74^{\circ} \mathrm{C}$. For polymerization of the Vipi Cril resin, the flask was placed in cold water until reach the temperature of $70^{\circ} \mathrm{C}$. Then, the temperature was maintained for 30 minutes. After 30 minutes, the temperature was raised to $100^{\circ} \mathrm{C}$ and subsequently kept for one and half hour. The flask was then left in water at the temperature of $40^{\circ} \mathrm{C}$ for 20 minutes before starting the deflasking. After polymerization, excess flash from the processing was removed using a sterilized trimming bur. The samples of each acrylic resins were divided into groups ( $\mathrm{n}=$ 3) according to the type of heat treatment and storage time that they were submitted:

Group 0: samples did not receive heat treatment and were not stored in water; Group 24: samples did not receive heat treatment and were stored in water for 24 hours (this procedure is recommended for the denture base acrylic resins); Group 48S: samples did not receive heat treatment and were stored in water for 48 hours; Group 48M: samples, individually, were exposed to microwave energy under power of $500 \mathrm{~W}$ for 3 minutes, Group 48B: samples were immersed in water at $55^{\circ} \mathrm{C}$ for 60 minutes.

For each cytotoxicity performed test, three specimens of each experimental condition were intended. Thus, nine samples were prepared for each tested acrylic resin $(\mathrm{n}=3)$. Prior to cytotoxicity tests, discs were ultrasonically cleansed in distilled water for $20 \mathrm{~min}$ and exposed to ultraviolet light for another $20 \mathrm{~min}$ to kill microorganisms that may have contaminated the discs during fabrication.

For the analysis of the cytotoxic effect of substances released from the samples, extracts were obtained of hydrosoluble substances of these samples [15]. For this, three samples from each experimental group were placed into vials with $3 \mathrm{ml}$ of Eagle's medium, supplemented with $7.5 \%$ of fetal bovine serum and 80 $\mu \mathrm{g} / \mathrm{ml}$ of gentamicin, and incubated at $37^{\circ} \mathrm{C}$ for 24 hours [15]. During this incubation period, the toxic substances probably were disseminated into the culture medium, thus forming the extracts which were used in MTT assay. A vial containing only $3 \mathrm{ml}$ culture medium was stored under the same conditions, thereby serving as a negative control group.

Possible cytotoxic effects of the substances released from the resins were evaluated by cell culture method. Thus, mouse fibroblast cells (L929) were propagated in Eagle's minimum essential medium (Institute Adolfo Lutz, Sao Paulo, Brazil) supplemented with $80 \mu \mathrm{g} / \mathrm{ml}$ of gentamicin and $7.5 \% \mathrm{v} / \mathrm{v}$ fetal bovine serum. The culture was maintained at $37^{\circ} \mathrm{C}$ in an atmosphere of $5 \%$ $\mathrm{CO}_{2} / 95 \%$ air.

For cytotoxicity analysis, MTT test was used. By this technique, the metiltetrazolium salt is incorporated into cell culture. The succinic dehydrogenase enzyme from viable cells breaks the structure of the tetrazolium salt to produce crystals of formazan in blue color, determining thereby the relative values of the intensity of blue color in specific spectrophotometer with a determinate wavelength. The greater mitochondrial activity, greater was the intensity of blue light and therefore, greater the number of viable cells. To perform the test, L929 mouse fibroblasts $\left(1 \times 10^{4}\right.$ $\mathrm{cell} / \mathrm{ml}$ ) in $100 \mu \mathrm{l}$ of the Eagle's medium were seeded into 96 well culture plates and incubated for 24 hours at $37^{\circ} \mathrm{C}$ in an air atmosphere containing 5\% $\mathrm{CO}_{2}$. After this incubation period, the culture medium was discarded, the cells remained attached to the bottom plate and $50 \mu \mathrm{l}$ of fresh culture medium were placed in each well of the plate along with $50 \mu$ l of the extract containing the substances released from specimens. The plate was incubated for 24 hours in $5 \% \mathrm{CO}_{2}$ at $37^{\circ} \mathrm{C}$. Four wells of a 96 well culture plate were used for each experimental (analysis in quadruplicate). 
Four wells of the plate did not receive the extract of released substances and received only $100 \mu \mathrm{l}$ of fresh culture medium supplemented with $7.5 \%$ fetal bovine serum and $80 / \mathrm{ml}$ gentamycin (negative control group). After 24 hours, $10 \mu$ l of metiltetrazolium salt (MT'T) was added to each well of the plate, which remained incubated for 4 hours at $37^{\circ} \mathrm{C}$ for the formation of formazan crystals, resulting from mitochondrial activity. Then, $100 \mu \mathrm{l}$ of MTT solubilizing solution were added to each well of the plate which was stirred gently until the dissolution the formazan crystals. Subsequently, the analysis of mitochondrial activity was performed on Multiscan spectrophotometer at a wavelength of 570 $\mathrm{nm}$. All procedures were performed twice on different days. Thus, each experimental condition was left with an eight replicates.

Evaluation of cell viability was performed by analysis of variance of two factors. It was adopted a significance level of $5 \%$. After statistical analysis, the materials were classified according to the cytotoxic effect: non-cytotoxic (cell viability above $75 \%$ in relation to control group), slightly cytotoxic (cell viability between 50 and $75 \%$ in relation to control group) moderately cytotoxic (cell viability between 25 and 50\% in relation to control group) and strongly cytotoxic (cell viability below $25 \%$ in relation to control group).

\section{Results}

Table 1 presents the means and standard deviations of cells viability in percentages compared to the control group, according to the acrylic resins and experimental groups: (G0) without storage and without treatment; (G24) 24 hours of storage in water; (G48S) 48 hours of storage in water without heat treatment; (G48B) stored in water for $48 \mathrm{~h}$ with water bath treatment and (G48M) water storage with oven heat treatment.

The analysis of variance showed no significant effect of the studied factors on cell viability. Table 2 presents the classification of resin compared to the control group. The means suggested that acrylic resins ranged from non-cytotoxic to moderately cytotoxic, but no statistical significance between these results. Furthermore, the water storage and thermal treatments reduced the cytotoxicity of the tested resins. In Figure 1, the mean cell viability was plotted along with standard errors associated with them.

\section{Discussion}

Biocompatibility studies are needed to evaluate the biological behavior of different materials. Many studies have been conducted to test the cytotoxicity of denture base and reline acrylic resins [9$11,16,18]$. However, these studies are based on imported resins, scarcely used in different prosthesis laboratories in Brazil. This study evaluated the cytotoxicity of denture base acrylic resins manufactured in Brazil. The effectiveness of additional thermal

Table 1. Mean and standard deviation (SD) of cell viability (\%) compared to control.

\begin{tabular}{|c|c|c|c|c|c|c|}
\hline \multicolumn{2}{|c|}{ Resin } & \multicolumn{5}{|c|}{ Groups } \\
\cline { 3 - 7 } & 0 & 24 & $48 \mathrm{~S}$ & $48 \mathrm{~B}$ & $48 \mathrm{M}$ \\
\hline \multirow{3}{*}{ Clássico } & Mean & 58,2 & 82,4 & 91,6 & 89,9 & 87,5 \\
\cline { 2 - 7 } & SD & 36,2 & 8,3 & 17,9 & 10,6 & 22,8 \\
\hline \multirow{2}{*}{ Lucitone } & Mean & 63,8 & 87,8 & 99,4 & 100,2 & 79,9 \\
\cline { 2 - 7 } & SD & 7,4 & 35,9 & 29,8 & 24,6 & 3,9 \\
\hline \multirow{2}{*}{ VipiCril } & Mean & 88,8 & 45,5 & 55,2 & 76,8 & 65,9 \\
\cline { 2 - 7 } & SD & 7,0 & 34,2 & 12,0 & 8,1 & 5,7 \\
\hline \multirow{2}{*}{ Onda Cryl } & Mean & 73,7 & 63,0 & 99,5 & 92,2 & 90,8 \\
\cline { 2 - 7 } & SD & 26,8 & 41,8 & 11,7 & 15,3 & 25,6 \\
\hline \multirow{2}{*}{ VipiWave } & Mean & 49,7 & 51,3 & 47,5 & 65,9 & 77,6 \\
\cline { 2 - 7 } & SD & 35,5 & 30,0 & 32,7 & 37,4 & 26,7 \\
\hline
\end{tabular}

Table 2. Resin classification compared to the control group.

\begin{tabular}{|c|c|c|c|c|c|}
\hline \multirow{2}{*}{ Resin } & \multicolumn{5}{|c|}{ Groups } \\
\cline { 2 - 6 } & 0 & 24 & $48 \mathrm{~S}$ & $48 \mathrm{~B}$ & $48 \mathrm{M}$ \\
\hline Clássico & 1 & 0 & 0 & 0 & 0 \\
\hline & & & & & \\
\hline Lucitone & 1 & 0 & 0 & 0 & 0 \\
\hline & & & & & \\
\hline VipiCril & 0 & 2 & 1 & 0 & 1 \\
\hline & & & & & \\
\hline Onda Cryl & 1 & 1 & 0 & 0 & 0 \\
\hline & & & & & \\
\hline VipiWave & 2 & 1 & 2 & 1 & 0 \\
\hline & & & & & \\
\hline
\end{tabular}


Figure 1. Average sample (column) and standard error (vertical bar) cell viability (\%) compared to control.

$\square 0 \mathrm{~h} \quad 24 \mathrm{~h}$ 图 $48 \mathrm{hS} \quad \mathbb{2} 48 \mathrm{~h} \mathrm{~B}$ 田 $48 \mathrm{~h} \mathrm{M}$

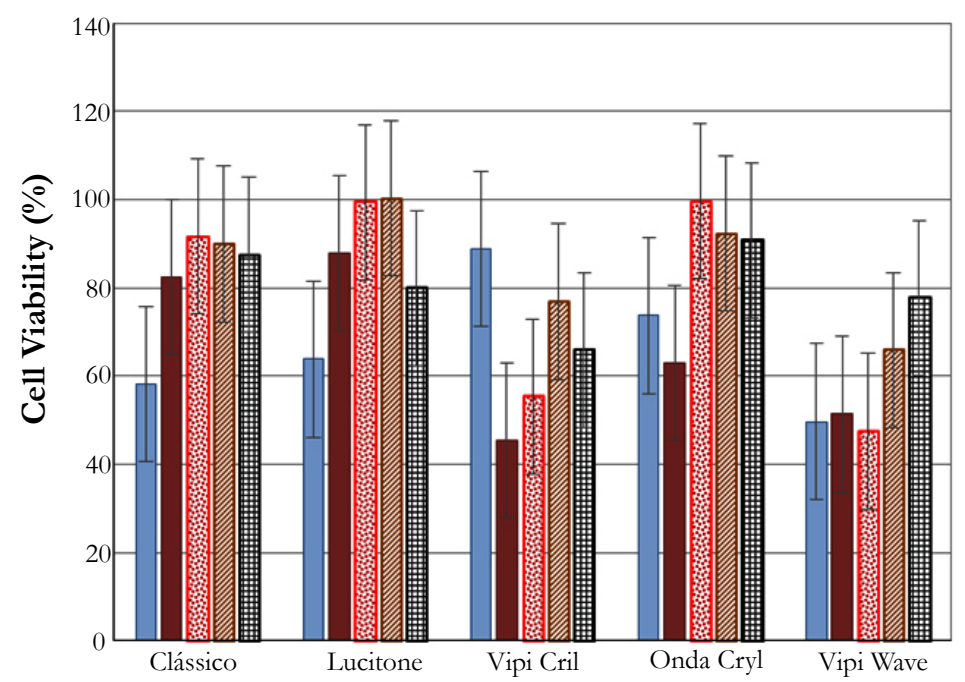

treatment and storage of water to reduce the cytotoxicity of these resins were also verified.

After statistical analysis, it was observed that there was no statistically significant difference between groups or between the studied acrylic resins. Although there was no statistically significant difference between the groups, it was observed that storage in water for 24 hours reduced the cytotoxicity of Lucitone 550 and Classic resins, which were ranked from slightly cytotoxic to noncytotoxic, and Vipi Wave, which was classified from moderately cytotoxic to slightly cytotoxic. After storage in water for 48 hours, there was a reduction of cytotoxicity of Vipi Cril and Wave CryI resins, which were classified from moderately cytotoxic to slightly and from slightly cytotoxic to non-cytotoxic, respectively. The reviewed literature indicated the importance of water storage to reduce the cytotoxicity of denture base acrylic resins. The storage of water can reduce the cytotoxicity of acrylic resins since much of the residual monomer found between the polymer chains can diffuse in water.

The heat treatments in water bath or microwave also reduced the cytotoxicity of some resins, although there was no statistically significant difference. The hot water bath decreased the cytotoxicity of Vipi Cril and Vipi Wave acrylic resins, which were ranked from slightly cytotoxic to non-cytotoxic and from moderately to slightly cytotoxic, respectively. Studies have found that, through immersion in warm water, the molecules of residual monomer diffusing quickly, reaching the remaining free radicals, providing additional polymerization reaction. Furthermore, during immersion in hot water, part of the monomer found between polymer chains, without being attached to them, diffuses in water66.

The microwave treatment decreased the cytotoxicity acrylic resin Vipi Wave, from moderately cytotoxic to non-cytotoxic. This reduction can be explained because the microwaves generate high frequency movements of the monomer molecules, causing an increase in internal heat and consequently higher conversion of monomer in polymer. Similar results were found by Jorge et al [10], which conducted a study with the purpose of comparing the effects of heat treatments in microwave or in hot water bath on the cytotoxicity of three denture acrylic resins after storage of the samples. The results of this study showed that all resins were slightly cytotoxic even after storage and thermal treatments did not reduce the cytotoxicity of the materials evaluated.

The differences in behavior between all tested materials could be explained by the composition of each material, the proportion powder/liquid or by polymerization methods of each resin. Based on a literature review, Jorge et al. [6, 17, 19], concluded that the cytotoxic effect of acrylic resins can be influenced from these factors.

The MTT assay was used based on different studies found in literature $[3,6,7]$. However, it is important to make the application of various tests for the cytotoxic effect analysis of the biomaterials or drug substances. According Miret et al [16], the best way to assess the cytotoxicity of a compound is to employ a series of essays that focus on different aspects of cell death. Jorge et al. [9], for instance, found in their study that the MTT assay was less sensitive than the incorporation of $3 \mathrm{H}$-thymidine test, which detected a statistically significant difference between experimental groups and control test. Finally, new studies using other methodologies for analysis of cell viability in different parameters should be performed to complement these results.

\section{Conclusion}

Within the limitations of this in vitro study, it was concluded that there was no difference statistic among the evaluated groups and on the acrylic resins studied. The resins ranged from moderately cytotoxic to non-cytotoxic. The water storage and thermal treatments reduced the cytotoxicity of the acrylic denture base resins tested.

\section{Acknowledgment}

This investigation was supported by Sao Paulo State Research Foundation (FAPESP - Grant 2011/18548-7).

\section{References}

[1]. Tanji M, Domitti SS, Consani RLX, Consani S, Sinhoretti MAC (2001) Polimerization influence on polimerization cycles on roughness and porosity of acrilyc resins. PGR - Pós-Grad Rev Fac Odontol São José dos Campos 
4(2): 71-78.

[2]. Craig RG, O'Brien W, Powers JM (1992) Plastics in prosthetics. Dental materials: properties and manipulation. (5th edn). St. Louis, Mosby - Year Book. p.267-292.

[3]. Kedjarune U, Charoenworaluk N, Koontongkaew S (1999) Release of methyl methacrylate from heat-cured and autopolymerized resins: Cytotoxicity testing related to residual monomer. Aust Dent J 44(1): 25-30.

[4]. Vallittu PK, Ruyter IE, Buykuilmaz S (1998) Effect of polymerization temperature and time on the residual monomer content of denture base polymers. Eur J Oral Sci 106(1): 588-593.

[5]. Hensten-Pettersen A (1988) Comparison of the methods available for assessing cytotoxicity. Int Endodont J 21: 89-99.

[6]. Jorge JH, Giampaolo ET, Machado AL, Vergani CE (2003) Cytotoxicity of denture base acrylic resins: a literature review. J Prosthet Dent 90(2): 190-193.

[7]. Jorge JH, Giampaolo ET, Vergani CE, Machado AL, Pavarina AC, et al. (2007) Biocompatibility of denture base acrylic resins evaluated in culture of L929 cells. Effect of polymerisation cycle and post-polymerisation treatments. Gerodontology 24(1): 52-57.

[8]. Braun KO, Del Bel Cury AA, Cury JA (1998) In vitro evaluation of polymerization effectiveness on acrylic dental resins through microwave energy in contact with metal. Rev Odont USP 12: 173-180

[9]. Jorge JH, Giampaolo ET, Vergani CE, Machado AL, Pavarina AC, et al. (2004) Cytotoxicity of denture base resins: effect of water bath and microwave postpolymerization heat treatments. Int J Prosthodont 17(3): 340-344.

[10]. Jorge JH, Giampaolo ET, Vergani CE, Pavarina AC, Machado AL, et al. (2009) Effect of microwave postpolymerization treatment and of storage time in water on the cytotoxicity of denture base and reline acrylic resins.
Quintessence Int 40(10): 93-100

[11]. Tay LY, Herrera DR, Quishida CC, Carlos IZ, Jorge JH (2012) Effect of water storage and heat treatment on the cytotoxicity of soft liners. Gerodontology 29(2): 275-280.

[12]. Jorge JH, Giampaolo ET, Vergani CE, Machado AL, Pavarina AC, et al. (2006) Effect of post-polymerization heat treatments on the cytotoxicity of two denture base acrylic resins. J Appl Oral Sci 14(3): 203-207.

[13]. Lefebvre CA, Schuster GS, Caughman GB, Caughman WF (1991) Effects of denture base resins on oral epithelial cells. Int J Prosthodont 4(4): 371376.

[14]. Tsuchiya H, Hoshino Y, Kato H, Takagi N (1993) Flow injection analysis of formaldehyde leached from denture-base acrylic resins. J Dent 21: 240-3.

[15]. International Standard Organization. ISO 10993-5 (1992) Biological evaluation of medical devices - part 5: Tests for cytotoxicity: in vitro methods. Washington, DC.

[16]. Miret S, De Groene EM, Klaffke W (2006) Comparison of in vitro assays of cellular toxicity in the human hepatic cell line HepG2. J Biomol Screen 11(2): 184-193

[17]. Chaves CA, Machado AL, Vergani CE, de Souza RF, Giampaolo ET (2012) Cytotoxicity of denture base and hard chair side reline materials: a systematic review. J Prosthet Dent 107(2): 114-127.

[18]. Ebrahimi SM, Vojdani M, Bahrani F (2012) Evaluation of cellular toxicity of three denture base acrylic resins. J Dent (Tehran) 9(4): 180-188.

[19]. Imazato S, Tarumi H, Ebi N, Ebisu S (2000) Cytotoxic effects of composite restorations employing self-etching primers or experimental antibacterial primers. J Dent 28(1): 61-67.

(**Appendix) 